\title{
Performance Appraisal of a Gamma-Type Stirling Engine
}

\author{
Kwasi-Effah C. C. ${ }^{1}$, Obanor A. I. ${ }^{1}$, Aisien F. A. ${ }^{1}$, Ogbeide O. O. ${ }^{2}$ \\ ${ }^{1}$ Department of Mechanical Engineering, University of Benin, Benin City, Nigeria \\ ${ }^{2}$ Department of Production Engineering, University of Benin, Benin City, Nigeria
}

\section{Email address:}

collinshicent@yahoo.com (Kwasi-Effah C.C)

\section{To cite this article:}

Kwasi-Effah C. C., Obanor A. I., Aisien F. A., Ogbeide O. O. Performance Appraisal of a Gamma-Type Stirling Engine. International Journal of Oil, Gas and Coal Engineering. Vol. 5, No. 4, 2017, pp. 51-53. doi: 10.11648/j.ogce.20170504.13

Received: February 3, 2017; Accepted: March 3, 2017; Published: October 23, 2017

\begin{abstract}
The demand for energy is expanding due to increase in population and fast industrialization which started in the 20th century. As domestic and industrial systems make use of the accessible energy produced by energy systems, technological headway is critical for these systems to maximally use the accessible energy sources available in the world. Thus, interest in Stirling engine technology is growing once again. This paper utilizes a third order quasi-steady flow model to predict the performance of an experimental gamma type Stirling engine at the heater temperature of $1145 \mathrm{~K}$ by simulating in MATLAB environment. A prediction error of $8.24 \%$ was obtained after comparing simulated performance with the experimental values. Empirical methods such as Beale and West analysis were also used to predict the performance of the Stirling engine. The quasi-steady flow model showed better accuracy when compared to other methods such as Beal and West analysis.
\end{abstract}

Keywords: Experimental Engine, Gamma Type, Modeling, Simulation, Stirling Engine

\section{Introduction}

The Stirling engine operates by cyclic compression and expansion of gas by a temperature difference across the engine to produce mechanical work. Heat is added persistently at a constant temperature to the expanding gas. This constant temperature heat expansion infers a high heat transfer rate through the cylinder, which is one of the primary challenges with the Stirling engine [1]. The traditional, reciprocating internal combustion (IC) engine, by comparison, burns an air-fuel mixture inside the cylinder to generate the heat and pressure which is converted to work at the crankshaft. The temperature is for the most part not constant amid the power stroke in the IC engine, but varies as the combustion and piston movement continues [2]. Since heat is supplied externally to the Stirling engine, different types of heat sources can be utilized such as: (a) Heat of combustion of any gaseous, fluid, or solid fuel, including all conventional fossil fuels and low-cost solid fuels, for example, petrol internal combustion engines, by contrast, have rather restrictive fuel property necessities to guarantee use of other fuel for combustion. (b) Solar irradiation, for instance using concentrated solar energy by solar dishes (c)
Heat from radioisotopes (d) Waste heat from industrial processes such as metal casting, glass production, and so on (e) Waste heat from heat recuperation devices e.g., heat from internal combustion engine exhaust. For the completion of the thermodynamic cycle, a Stirling engine must be cooled externally to relieve the pressure on the piston and along these lines allow it to return it its initial position. Cooling can be achieved in different ways such as: (a) Forced or free convection cooling e.g, air flow over fins (b) Water, ethylene glycol, or a mixture of both, circled through a cooling jacket encompassing the cold side of the engine. Here, the coolant is normally kept cool by an air-cooled heat exchanger like a vehicle's radiator.

In addition, the Stirling engine cycle is "reversible;" which means that, mechanical power input can be utilized to give cooling. This trademark additionally separates the Stirling engine cycle from the cycle that creates power in the internal combustion engine. External combustion allows for more controlled burning of the fuel, which can bring about lower emissions. Constant external combustion likewise gives the additional advantage of a great deal less noise and vibration 
when contrasted with internal combustion engines [3, 4]. This paper aims to investigate the performance of a gammatype Stirling engine

\section{Methodology}

The method of differential control volume was used to develop a third order quasi-steady flow model. The gamma type Stirling engine was configured as five control volumes serially linked having impeccable heat exchangers including the regenerator. Both the expansion and compression space were considered to be adiabatic. A summary of the assumptions made are listed as follows: (i) The working gas in each control volume is considered as a perfect gas. (ii) Compression and expansion space are considered to be adiabatic. (iii) The pressure is initially constant across the system. (iv) The total mass of gas in the system is assumed to be constant thus no leakage (v) The enthalpy transported across the interfaces assumes the value of the upstream temperature and mass flow rate (vi) The heat exchangers are initially perfect. The model was simulated using MATLAB with input data obtained from an experimental gamma type Stirling engine.

Experiment was aimed at measuring the power output of the experimental engine. Before the engine was started, the gas tank was placed on the weighing balance and the initial gas mass was recorded. The gas burner was then fired and the gas flow rate was kept constant throughout the testing. The engine was heated up until it reaches the operating temperature. The engine was then started and run until the steady condition is reached. The engine was loaded by adding dead weight on the weight hanger until the flywheel stops. After that, the engine speed values, spring balance readings and all temperatures from the thermocouples were recorded.

\section{Results and Discussion}

Table 1 and 2 shows the simulated numeric result of the experimental engine and Figure 1 and 2 shows the result of the simulated performance of the experimental engine.

Table 1. Simulated result of the experimental gamma type Stirling engine.

\begin{tabular}{ll}
\hline Parameters & Values \\
\hline Total mass of gas & $0.66 \mathrm{gm}$ \\
Expansion Work (We) & $0.8865 \mathrm{Joules}$ \\
Compression Work (Wc) & $-0.2385 \mathrm{Joules}$ \\
Indicated power & $4.86 \mathrm{Watts}$ \\
Indicated efficiency & $73.1 \%$ \\
\hline
\end{tabular}

Table 2. Result of the experimental engine at $1145 \mathrm{~K}$.

\begin{tabular}{llllll}
\hline Frequency $(\mathbf{H z})$ & Heater temperature $(\mathbf{K})$ & Cooler temperature $(\mathbf{K})$ & Torque $(\mathbf{N m})$ & Brake power $(\mathbf{W})$ & Brake thermal efficiency $(\%)$ \\
\hline 6.72 & 1145 & 308.46 & 0.083 & 3.50 & 42.60 \\
\hline
\end{tabular}

Table 3. Summary of the experimental engine performance.

\begin{tabular}{ll}
\hline Simulated indicated power & $4.86 \mathrm{~W}$ \\
Actual indicated power & $4.49 \mathrm{~W}$ \\
Prediction error & $8.24 \%$ \\
\hline
\end{tabular}

Table 4. Comparison between Beale, West and quasi-steady flow model.

\begin{tabular}{lll}
\hline Beale & West & Quasi-steady flow model \\
\hline $2.29 \mathrm{~W}$ & $2.61 \mathrm{~W}$ & $3.50 \mathrm{~W}$ \\
\hline
\end{tabular}

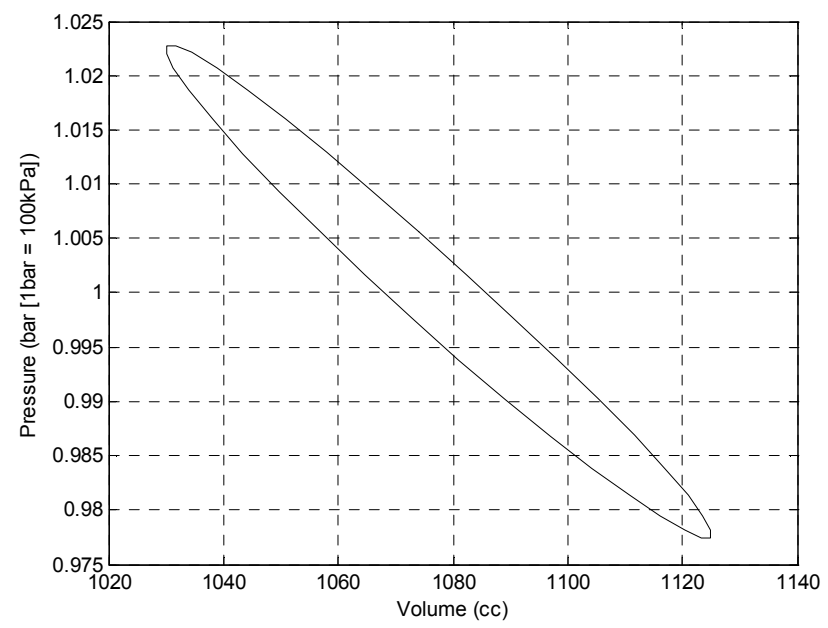

Figure 1. Pressure volume diagram of the simulated engine.

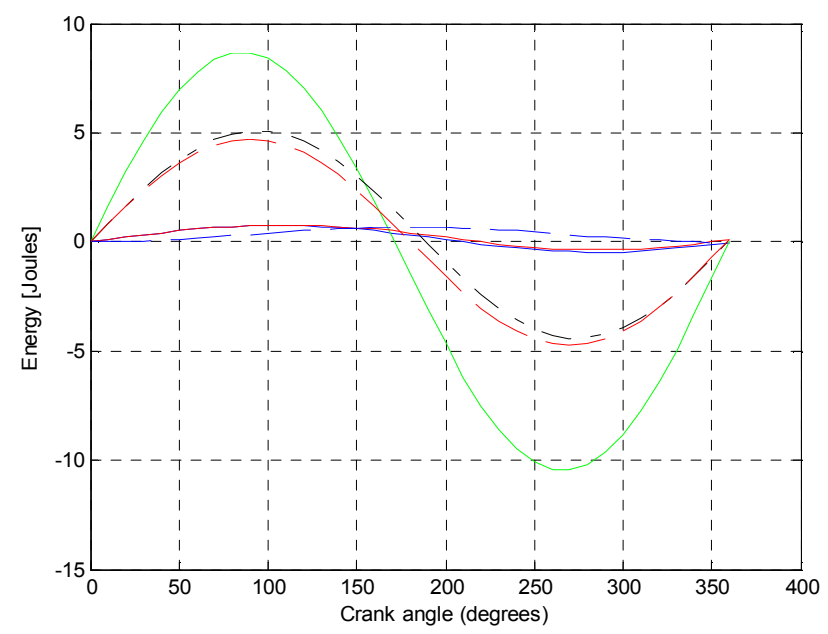

Figure 2. Energy vs crank angle.

Table 1 shows the values of the simulated performance as having an indicated power output of $4.86 \mathrm{~W}$ and efficiency of $73.1 \%$. The fluid property behavior is shown in Table 3 . Figure 1 shows the $\mathrm{pV}$ diagram of the simulated experimental engine. Figure 2 shows the energy variation in the cooler, heater and regenerator. During the experimental 
investigation it was observed that by increasing the heater temperature, due to metallurgical constraints, the maximum attainable heater temperature for this experimental engine was limited to $1145 \mathrm{~K}$ in order to avoid damage. This is a significant practical challenge relating to Stirling engine design. Hence the engine performance can continuously increase by increasing the temperature gradient and working pressure. By comparing the experimental result and simulated result of the engine, a power output difference of $0.37 \mathrm{~W}$ was obtained having about $8.24 \%$ absolute prediction error. Error in prediction may be due to error in instrumentation, human error, mechanical friction and slight leakages. Thus by utilizing this model it is possible to observe the effect of the various parameters for optimization purpose and to fabricate a gamma type Stirling engine of varying capacity with little variation on the performance of the engine prototype. The energy versus crank angle diagram is the impressive measure of heat transferred in the regenerator over the cycle. This has shown that the engine performance depends basically on the regenerator effectiveness and its capacity to accommodate high heat fluxes. Essentially the energy rejected by the gas to the regenerator matrix in the first half of the cycle is equal to the energy consumed by the gas from the regenerator matrix in the second half of the cycle, along these lines the net heat transfer to the regenerator over the cycle is zero. The significance of the regenerator was not comprehended for around 100 years in the wake of Robert Stirling's unique patent depicting the function and significance of the regenerator. For the energy crank angle diagram, we see specifically that the expansion space work done experiences distinctive process from that of heat transfer in the heater, however toward the end of the cycle they have equal qualities. So also for the compression space work done and the heat transferred to the cooler. Hence for this model, we can say that the work done in the expansion and compression space over a complete cycle is given by the individual cooler and heater heat exchangers. [5] presented a model which takes into account the effectiveness of the drive mechanism in the Schmidt theory to analyze the engine performance of the gamma type configuration. The results of experiments on a $10 \mathrm{~kW}$ gamma type Stirling engine demonstrated that the mechanical effectiveness of the engine has a strong influence on the shaft power of engine. Martini presented an isothermal model based on Schmidt theory and taking into account heat losses and pressure losses [6]. The temperatures of hot and cold gases were obtained by taking into account temperature drops in the heater and cooler. His model was validated using the experimental data obtained from GPU-3 Stirling engine. There was $20 \%$ error compared to experimental results [7]. Roy and Tew compared their model with experimental data from the GPU-3 Stirling engine. When the regenerator friction factor was increased by factors of 4.0 and 2.6 for hydrogen and helium, respectively, the model over predicted both brake power and efficiency by $5 \%$ to $30 \%[8,9,10]$.

\section{Conclusion}

A gamma type experimental engine performance was investigated at the designed temperature value of $1145 \mathrm{~K}$ for assertion. By comparing the experimental result and simulated result of the engine, a power output difference of $0.37 \mathrm{~W}$ was obtained which constituted about $8.24 \%$ absolute prediction error. The energy diagram has been able to show that the efficiency of the system depends majorly on the regenerator effectiveness. The quasi-steady model showed more accuracy compared to other methods such as the Beale and West analysis. The quasi-steady flow model can also be beneficial for parametric and optimization studies for better design of the gamma type Stirling engine.

\section{References}

[1] Blank, F. A., (2011). Power optimized work for reciprocating internally reversible Stirling-like heat engine cycles with regeneration and linear external heat transfer. Journal of Applied Physics, 84 (5): 238-292.

[2] Chen, N. C. and Griffin, F. P., (1983). A review of Stirling engine mathematical models. Technical Report. Report No ORNL/CON 135, OAK Ridge National Laboratory, Tennessee.

[3] Dixit, D. K, Ghodke, SV (2012). Renewable energy powered Stirling engines - a viable energy alternative. In: Sayigh AAM, editor. Renewable energy technology and the environment. Proceedings of the second world renewable energy congress, 2: 934-8.

[4] Formosa, F. and Despesse, G., (2010). Analytical model for Stirling cycle machine design. Energy Conversion and Management, 51: 1855-1863.

[5] Gheith, R., Aloui F. and Ben S. N., (2012). Study of the regenerator constituting material influence on a gamma type Stirling engine. Journal of Mechanical Science and Technology, 26 (4): 1251-1255.

[6] Toda, F. S., Iwamoto, K. and Nagajima, N., (2007). Development of low-temperature difference Stirling engine behavior of the mechanism effectiveness for the performance prediction method. Proceeding of 13th international Stirling engine conference, Tokyo.

[7] Kolin, I., (2001). Ideal Stirling cycle in Alpha, Beta and Gamma engine. Proceedings of the 10th Stirling engine conference 24th - 26th September, Osnabruck, Germany.

[8] Roy, C. and Tew, J. R., (1983): Computer program for Stirling engine performance calculations. DOE/NASA/51040-42 NASA TM-82960.

[9] Hsu, S. T. Lin F. Y. and Chiou, J. S., (2013). Heat-transfer aspects of Stirling power generation using incinerator waste energy. Journal of Renewable Energy, 28: 59-69.

[10] Kim, S. Y., (2006): Specific power estimations for free-piston Stirling engines. 4th International Energy Conversion Engineering Conference and Exhibit, San Diego: 80-19. 